\title{
Application of information entropy in fault diagnosis of high speed train wheel set
}

\author{
Mingming Liu, a , Yindong $\mathrm{Ji}^{2, \mathrm{~b}}$, Longlong Chen ${ }^{3, \mathrm{c}}$, Wei Dong ${ }^{4}$, Xinya Sun ${ }^{5}$ \\ 1,2,4,5 Tsinghua National Laboratory for Information Science and Technology, Tsinghua University, \\ Beijing 100084, China \\ ${ }^{3}$ Military representatives office in Baotou 447 factory, Baotou, China \\ aImm13@mails.tsinghua.edu.cn, bjyd@tsinghua.edu.cn, 'longouzi@163.com
}

\begin{abstract}
Keywords: information entropy; high speed train; wheel set; fault diagnosis
Abstract. Because of the characteristics of the high speed train and its operating environment, the high speed train is in an unstable state. As a very important part of the high speed train, the train wheel set is also influenced by other external factors which are very complicated. In this paper, the vibration characteristics of a number of key components of the train wheel assembly are studied by using the theory of information entropy, and the diagnosis of the faults of the wheel is completed by using the basic concepts and rules of D-S evidence theory. In the end, the paper takes the wheel set failure of CRH3 high speed train as an example. Through theoretical research and experimental results, this paper also shows that the information entropy feature extraction and fusion method can realize the quantitative characterization and system operation state evaluation of multi-source and multi-level signal characteristics. It is also proved that the method can effectively reduce the uncertainty of fault diagnosis and improve the accuracy of fault diagnosis.
\end{abstract}

\section{Introduction}

Due to long time and high load in the bad working conditions with multi dust and large temperature variation, the train wheel set has become one of the most frequent failures of the high speed train. In addition to the conventional impact and vibration, the wheel set is also affected by the external factors caused by the additional vibration and shock such as the uneven railway and irregular turnout, so its actual operation is very complicated. At present, the real-time monitoring and data acquisition system of high speed train has been developed and improved. The large amount of operating data which is collected from the sensors located at each position of the high speed train contains a wealth of information about the fault state and the degree of the high speed train wheel set. However, how to analyze and use these data effectively is a hot and difficult problem for the fault diagnosis and health maintenance of high speed train wheel set.

\section{Fault and Characteristic Extraction of High speed Train Wheel Set}

There are many electric machine assembling methods of high speed train wheel set with various formations, but they all consist of several core components. Take the electric machine assembling of a high speed train wheel set as example, it has three bogies with each composed by two wheel set electric machines. The electric machine assembling of this wheel set consists of seven parts such as traction motor, traction gear box, gear traction arranger, wheel set assembly, axle box assembly, axle box trolley and motor suspension.

In the actual operation and maintenance, the fault types of high speed train wheel are generally divided into 6 levels, which are divided into Table 1: 
Table 1 Fault classification of high speed train wheel set

\begin{tabular}{cl}
\hline Wheel set failure level & \\
\hline Completely normal & State is very good \\
normal & Good condition, suitable for long-term operation \\
Basic normal & There is an abnormal symptom, can not run for a long time, but can run for a period of time \\
Minor failure & There are more serious abnormal signs, should take measures, such as adjusting the operation \\
& mode or load \\
failure & Wheel set has been a serious abnormal signs, can not run for a long time, should be in a short \\
Severe failure & time to repair \\
\hline
\end{tabular}

Hereinto, the axle box bearing and traction gear of high speed train are the key components of wheel set. Because they have been in high speed bearing working status for a long time, the contact surface is subject to alternating contact stress, which is apt to trigger pitting, crack or other defects; malfunction such as wheel set rupture. It then could cause the accidents of axle cut as well as oil burning of high speed walking components.

Vibration signal is an important characteristic parameter of wheel set's status. When the mechanical status of wheel set changes, the amplitude and peak of vibration signal generated by wheel set will change too. For example, if the machine has fault of mass unbalance, the peak of vibration signal will increase obviously; and if the wheel set appears malfunction of misalignment, the amplitude of vibration signal will be markedly increased too.

Here takes the single partial failure of high speed wheel set on rolling bearing moving parts as study object to analyze and the bearing of high speed train can be regarded as a vibration system. Through establishing kinetic equations, the vibration feature can be figured out as follows:

$\mathrm{M} \ddot{\mathrm{x}}+\mathrm{C} \dot{\mathrm{x}}+\mathrm{Kx}=\mathrm{F}_{0}(\mathrm{t})+\mathrm{F}_{1}(\mathrm{t})$.

Where, $\mathrm{X}$ is contact point's relative displacement in radial direction; $\mathrm{M}$ is the equivalent weight of bearing system; $\mathrm{C}$ is the damping of rolling bearing; $\mathrm{K}$ is the contact stiffness of rolling bearing. $\mathrm{F}_{0}(\mathrm{t})$ is system initial exciting force, which includes the acting force exerted by high speed train wheel track contacting system on bearing through bogie. $F_{1}(t)$ is partial failure exciting force and it covers the motivation on faultiness generated by high speed train wheel set, which is mainly the effect of fault function and contact stiffness.

\section{Wheel set diagnosis model based on multi source signal information entropy fusion}

The development of information entropy theory derives from the information theory that is established to solve the transmission problem of information communication by American scientist Shannon with main research content of quantitative description and index.

When we test and diagnose fault by information entropy, the chief work is to carry out feature detection as well as quantitative description of state parameter of the system under test. This information theory analytical method regards the system under test as the information source model and the feature extraction of system state is the cognitive process of extracting relevant information from information source model. The specific method is to carry out quantitative description and analysis of information source feature, make quantitative representation of testing parameters such as correlation, singularity, uncertainty as well as inner features by using the different information measurement indexes of the system under test, and then make it become the reference of signal analysis and fault diagnosis.

When conducting multi-omen information fusion diagnosis of wheel set fault, we can count each vibrating transducer as a communication channel in the perspective of information theory and extract the feature information of multi-omen vibration signal through two vibrating transducers, which is two information channels. The conclusion obtained through analysis is also applied in the situation of multi-channel for single communication channel is just a special case of it. Thus, the conclusion can also be used in the situation of extracting feature information by single vibrating transducer.

Therefore, the wheel set diagnosis model based on multi source signal information entropy fusion can refer to the feature signal parameter extracted firstly, then figure out HD through the computing 
method of machine health degree secondly; and then finish the diagnosis as well as decision of wheel set fault level by using the basic concept and compound rule of Dempster-Shafer evidence theory and fusing multi-omen feature information. What showed in Fig.1 is the specific procedure of using Dempster-Shafer evidence theory to implement multi source signal information entropy fusion of wheel set.

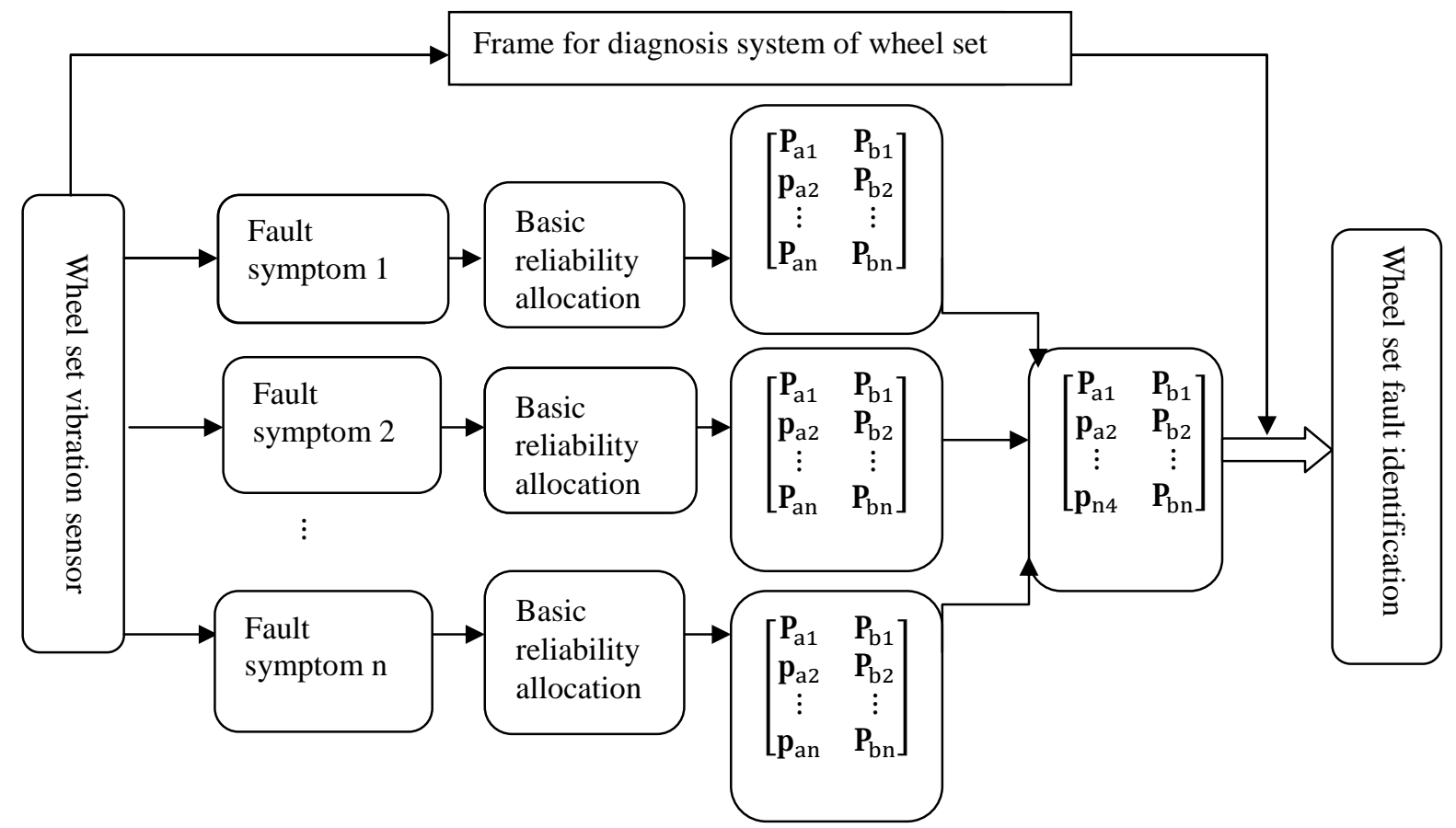

Fig.1 The wheel set diagnosis model based on multi source signal information entropy fusion

In Fig. 1, it input the value of vibration amplitude and vibration frequency of vibrating transducer measured by high speed wheel set into fault diagnosis system to calculate basic reliability allocation $\mathrm{m}_{\mathrm{i}}=\mathrm{HD}_{\mathrm{i}} / \mathrm{HD}$ and the degree of basic reliability that represents omen $\mathrm{i}$. The evidence interval $\left[\mathrm{P}_{\mathrm{aj}}, \mathrm{P}_{\mathrm{bj}}\right]$ can be acquired by basic reliability allocation. Where, $\mathrm{P}_{\mathrm{aj}}=\mathrm{p}\left(\mathrm{y}_{\mathrm{j}} \mathrm{l}, \mathrm{x}_{\mathrm{i}}\right)$, it stands for the profitability of $y_{j}$ fault omen in the condition of fixed wheel set type $x_{i} \cdot P_{b j}=1-P_{b j}=1-$ $p\left(y_{j} l, x_{i}\right)$ expresses the profitability of $y_{j}$ fault that cannot be denied in the condition of fixed wheel set type $\mathrm{x}_{\mathrm{i}}$. When implanting various omen diagnosis on wheel set, calculate the $\left[\mathrm{P}_{\mathrm{a}}, \mathrm{P}_{\mathrm{b}}\right]$ of each omen and then compute infusion $\left[\mathrm{P}_{\mathrm{a}}, \mathrm{P}_{\mathrm{b}}\right]$ by using Dempster-Shafer compound rule.

This assumes that $\mathrm{y}_{1}$ and $\mathrm{y}_{2}$ represents the eigenvectors extracted by two vibrating transducers in different sections located in wheel set from its vibration state. The output of fusion system is $\mathrm{z}$, which stands for the output eigenvectors after information infusion with statistical property can be expressed by $\mathrm{p}\left(\mathrm{zl} \mathrm{y}_{1}, \mathrm{y}_{2}\right)$. The diagnosis method of wheel set fault diagnosis infusion system can be divided into two categories: One is the different diagnosis results of different probability outputs, which can be described as: $\exists \mathrm{z}$, there meet the conditions $\mathrm{p}\left(\mathrm{z} / \mathrm{y}_{1}, \mathrm{y}_{2}\right) \leq 1$ and $\sum_{\mathrm{z}} \mathrm{p}\left(\mathrm{z} \mid \mathrm{y}_{1}, \mathrm{y}_{2}\right)=1$. Another is appoint a fixed diagnosis output $\mathrm{z}$ as for any $\mathrm{y}_{1}$ and $\mathrm{y}_{2}$. After the definition infusion entropy $\mathrm{H}$ $\left(\mathrm{zl}_{1}, \mathrm{y}_{2}\right)$ stands for system output $\mathrm{y}_{1}$ and $\mathrm{y}_{2}$, the system outputs the average uncertainty of $\mathrm{z}$.

If there assume that $\mathrm{z}$ is not independent from $\mathrm{y}_{1}$ and $\mathrm{y}_{2}$, we can get from the information theory that the conditional entropy of infusion system satisfies:

$\mathrm{H}\left(\mathrm{zl} \mathrm{y}_{1}, \mathrm{y}_{2}\right) \leq \mathrm{H}\left(\mathrm{zly}_{\mathrm{i}}\right) \quad \mathrm{i}=1,2$

$\mathrm{H}_{0}\left(\mathrm{zl} \mathrm{y}_{1}, \mathrm{y}_{2}\right) \leq \mathrm{H}\left(\mathrm{z} \mid \mathrm{y}_{\mathrm{i}}\right)$.

When $\mathrm{y}_{1}$ and $\mathrm{y}_{2}$ are independent mutually, the compression ability of infusion system on output uncertainty is minimum, which means hereinto, $\mathrm{H}_{0}\left(\mathrm{zl}_{1}, \mathrm{y}_{2}\right)$ is the information entropy of system output when $\mathrm{y}_{1}$ and $\mathrm{y}_{2}$ are independent mutually and $\mathrm{H}\left(\mathrm{zl}_{\mathrm{y}_{1}}, \mathrm{y}_{2}\right)$ is the information entropy of system output under general circumstance.

As for the first property, by using the Shannon's Theorem can prove similarly:

$\mathrm{H}\left(\mathrm{Xl}_{1}, \mathrm{y}_{2}\right) \leq \mathrm{H}\left(\mathrm{Xl}_{\mathrm{i}}\right), \mathrm{i}=1,2$.

According the property mentioned above, the difference of mutual information satisfies: 
$\mathrm{I}\left(\mathrm{X} ; \mathrm{y}_{1}, \mathrm{y}_{2}\right)-\mathrm{I}\left(\mathrm{X} ; \mathrm{y}_{2}\right)=\mathrm{H}\left(\mathrm{Xl} \mathrm{y}_{1}\right)-\mathrm{H}\left(\mathrm{Xl}_{\mathrm{y}_{1}}, \mathrm{y}_{2}\right) \geq 0$

It can be known according to above that in the diagnosis of high speed wheel set, the $X \rightarrow Y \rightarrow Z$ will construct a Markov Chain if there adopts vibrating transducer only to measure single omen vibration signal and the rule of $\mathrm{I}(\mathrm{X} ; \mathrm{Z}) \leqslant \mathrm{I}(\mathrm{X} ; \mathrm{Y})$ will appear.

Judge by using minimum misjudgment probability, when the fault category number of wheel set $n$ $=6$, misjudgment probability $\mathrm{P}_{\mathrm{e}}$ and $\mathrm{H}(\mathrm{X} \mid \mathrm{Y})$ has following relationship:

$\mathrm{P}_{\mathrm{e}} \leq \frac{1}{6} \mathrm{H}(\mathrm{X} \mathrm{Y})$.

If use Fano limitation to decide the lower bound of $\mathrm{P}_{\mathrm{e}}$, there can have:

$\mathrm{P}_{\mathrm{e}} \geq\left[\mathrm{H}(\mathrm{X} \mathrm{Y})-\mathrm{H}\left(\mathrm{P}_{\mathrm{e}}, 1-\mathrm{P}_{\mathrm{e}}\right)\right] / \log 5$.

In the wheel set fault diagnosis fusion system which adopts vibrating transducer to measure multi-omen vibration signal, it uses minimum misjudgment probability rules and Fano limitation to decide the upper as well as lower bound of $\mathrm{P}_{\mathrm{e}}$ simultaneously. The upper and lower bound relationship of misjudgment probability $\mathrm{P}_{\mathrm{e}}$ regarding to $\mathrm{H}\left(\mathrm{Xl}_{1}, \mathrm{y}_{2}\right)$ is:

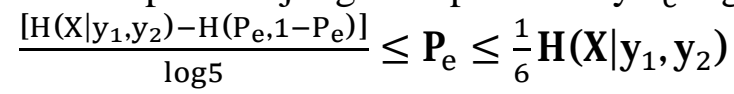

According to the property of $\mathrm{H}\left(\mathrm{Xl}_{\mathrm{y}_{1}}, \mathrm{y}_{2}\right) \leq \mathrm{H}\left(\mathrm{Xly}_{\mathrm{i}}\right)$ stated earlier, and through analyzing the formula above, it can be known that the upper and lower bound of misjudgment probability $\mathrm{P}_{\mathrm{e}}$ of wheel set fault diagnosis fusion system based on multi-omen vibration signal is lower than the misjudgment probability $\mathrm{P}_{\mathrm{e}}$ of wheel set fault diagnosis fusion system based on single omen vibration signal. This indicates that the degree of information uncertainty of wheel set fault diagnosis fusion system based on multi-omen vibration signal is less than that of wheel set fault diagnosis fusion system based on single omen vibration signal. That is to say, the output of wheel set fault diagnosis fusion system based on multi-omen vibration signal can obtain more information amount in regard to wheel set fault.

It can be seen from the property above that in wheel set fault diagnosis, the more diversity of extracted vibration signal features, the lower correlation, uncertainty of fault diagnosis output as well as misjudgment probability will be. Thus, the obtained diagnosis results of wheel set will be more accurate.

\section{Fault Diagnosis Example of CRH3 Type High speed Train Wheel Set}

The following takes the fault of CRH3 type high speed train wheel set as example and verified by applying the diagnosis of information entropy on wheel set. The high speed train selected in the example is equipped with "high speed train fault diagnosis system", which collects and records real-time vibration signal of wheel set in its actual motion process.

When we carry out fault diagnosis of CRH3 type high speed train wheel set, there conduct single and multi-omen feature information extraction separately; implement fusion process on multi-omen feature information by Dempster-Shafer evidence theory and get diagnosis conclusion at last. What showed in Table 2 are the data relevant to vibration signal feature of wheel set and after fusion process as well as the diagnosis conclusion acquired from these data.

In Table 2, the data in the first and second line are all testing data of wheel set diagnosis through adopting single omen diagnosis signal. Hereinto, the result in first line took amplitude as single omen to implement fault diagnosis; the result in second line conducted fault diagnosis by using frequency as single omen whereas the result in third line carried out fault diagnosis through adopting the multi-omen of amplitude as well as frequency and making use of information infusion technology.

Table 2 Fault classification of high speed train wheel set

\begin{tabular}{|c|c|c|c|c|c|c|}
\hline Feature & Normal $[\mathrm{B}, \mathrm{P}]$ & $\begin{array}{c}\text { Minor failure } \\
{[\mathrm{B}, \mathrm{P}]}\end{array}$ & failure $[\mathrm{B}, \mathrm{P}]$ & $\begin{array}{c}\text { Severe failure } \\
{[\mathrm{B}, \mathrm{P}]}\end{array}$ & Uncertainty & $\begin{array}{l}\text { Diagnosis } \\
\text { result }\end{array}$ \\
\hline $\begin{array}{c}\text { Amplitude } \\
\text { parameterC1 }\end{array}$ & {$[0.243,0.348]$} & {$[0.248,0.374]$} & {$[0.218,0.336]$} & {$[0.159,0.313]$} & 0.132 & Uncertain \\
\hline $\begin{array}{c}\text { Frequency } \\
\text { distributionC2 }\end{array}$ & {$[0.235,0.338]$} & {$[0.256,0.380]$} & {$[0.147,0.262]$} & {$[0.234,0.391]$} & 0.128 & Uncertain \\
\hline $\begin{array}{c}\text { Fusion of } \mathrm{C} 1 \\
\text { and } \mathrm{C} 2\end{array}$ & {$[0.187,0.199]$} & {$[0.424,0.457]$} & {$[0.260,0.296]$} & {$[0.101,0.148]$} & 0.028 & $\begin{array}{l}\text { Minor } \\
\text { failure }\end{array}$ \\
\hline
\end{tabular}


It can be seen from Table 2 obviously that the uncertainty of two diagnosis of using amplitude or frequency to conduct single omen vibration signal are 0.132 and 0.128 separately, which are far more greater than the uncertainty (0.028) of diagnosis by fusing amplitude parameter and frequency as multi-omen vibration signal. According to the ultimate result, it can be seen that the diagnosis result of taking amplitude or frequency as single omen is uncertain, which cannot distinguish the fault type of wheel set. This is because the [B, P] value of different wheel faults showed in Table 2 approaches to the $[\mathrm{B}, \mathrm{P}]$ value in normal condition but the multi-omen vibration signal diagnosis after fusing frequency and amplitude makes the difference between $[\mathrm{B}, \mathrm{P}]$ value in minor fault type and $[\mathrm{B}, \mathrm{P}]$ value in normal condition is larger. Meanwhile, the $[\mathrm{B}, \mathrm{P}]$ value in other fault types is close to the $[\mathrm{B}, \mathrm{P}]$ value in normal condition and the diagnosis result can be obtained that the wheel set of this high speed train is in minor failure condition.

\section{Conclusion}

Aimed at the problems existing in the diagnosis of high speed train wheel set, this article systematically researched on the feature extraction method and computational model of testing parametric information entropy, constructed information fusion analytical model of multisource signal and provided new approach for the quantitative description of multisource \& multilevel signal feature as well as fault diagnosis of complex system through applying information theory and data fusion. The theoretical research and experimental results also showed that, the information entropy extraction and fusion method proposed in this article can realize the judgment of multisource \& multilevel signal feature's quantitative characterization and system running status and carry out quantitative description of system status evolution laws with features of non-linear and non-smooth running. All these will provide a brand new approach for solving complex fault diagnosis with characteristics of parameter coupling status as well as multisource parameter.

\section{Acknowledgements}

Resrach supported by the Natural Science Foundation of China under Grants 61104019, 61374123, and the Tsinghua University Initiative Scientific Research Program.

\section{References}

[1] A.P. Dempster, Upper and lower probabilities induced by a multi-valued mapping, Ann. Mathematical Statistics. 38 (1967) 325-339.

[2] Adjrad M, Belouchrani A, Estimation of multicomponent polynomial-phase signals impinging on a multisensor array using state-space modeling, J. Transactions on Signal Processing. $1(2007) 32-45$.

[3] LI Jian-lan, Fault Diagnosis of a Rotary Machine Based on Information Entropy and Rough Set, J. International Journal of Plant Engineering and Management. 4(2007)199-206.

[4] HUQingHua, Information entropy for ordinal classification, J. Science China(Information Sciences). 6(2010)1188-1200.

[5] BAO TengFei, Analysis of crack propagation in concrete structures with structural information entropy, J. Science China(Technological Sciences). 7(2010)1943-1948.

[6] Xiujie Qu, Novel detection method for infrared small targets using weighted information entropy, J. Journal of Systems Engineering and Electronics. 6(2012)838-842.

[7] CHEN Fei, A Diagnosis Method of Vibration Fault of a Steam Turbine Based on Information Entropy and Grey Correlation Analysis, J. International Journal of Plant Engineering and Management. 4(2009)206-211. 